\title{
Bilingual Programs in Jaffna: An Appraisal
}

\section{T. Karunakaran}

Senior Lecturer in ELT, English Language Teaching Center, University of Jaffna, Sri Lanka

\section{Email address:}

karuenglish@yahoo.com

\section{To cite this article:}

T. Karunakaran. Bilingual Programs in Jaffna: An Appraisal. Humanities and Social Sciences. Vol. 2, No. 1, 2014, pp. 5-10. doi: $10.11648 /$ j.hss.20140201.12

\begin{abstract}
This paper tries to bring the actual practice of bilingual education in Jaffna schools. A research was undertaken in order to appraise the bilingual programs being conducted in the Jaffna schools, particularly in the post civil war scenario. The study looks into current situation of bilingual education programs in place in the two schools, Jaffna Hindu Ladies' College (JHLC) and J/Vembadi High School (VGHC). A pilot study gave a lot of insights to focus on the key issues of the present study, and also it helped the researcher to develop research tools and decide the sample size. This study captured different perspectives of teachers and students from two schools and also the other socio-linguistic and socio-cultural factors that might have an impact on the effective operation of bilingual programs in Jaffna.
\end{abstract}

Keywords: Bilingual Programs, Bilingual Teachers, Bilingual Students, Socio-Economic Factors

\section{Societal Information in Establishing a Bilingual Education Program}

Different types of bilingual education programs make implicit assumptions about the kind of language situation that exists in a given society and about the kind of language situation that should exist in that community. Program developers should make their assumptions explicit and try to test the validity of these assumptions by gathering a variety of data regarding the societal functions of community languages and existing attitudes toward them, both before and during the development of bilingual education programs. Gardner, Reynolds and Kuehne (1967 cited in Karunakran, 2012:113) suggest that the way in which a school or community goes about establishing a bilingual program will mainly identify the structure the program will take. Though assumption underlies the suggestions here for gathering information beyond that usually available in school records, data is used as part of the process of deciding whether to establish a bilingual program and what kind of program to establish. In this early stage of development the following information seems minimal, if the school and community are going to make conscious, explicit decisions about an appropriate bilingual program: 1. A survey that would establish the languages and varieties employed by both parents and children, by societal domain or function. 2. Some rough estimate of their relative performance level in each language, by societal domain. 3. Some indication of community (and school staff) attitudes toward the existing languages and varieties, and toward their present allocation to domains. 4. Some indication of community (and school staff) attitudes toward changing the existing language situation (Gardener, Reynolds \& Kuehne, 1967:499-500 cited in Karunakaran, 2012:113-114).

\subsection{Varieties of Bilingual Education}

The term bilingual education is an inaccurate umbrella term that applies both to classrooms- where formal instruction aims to foster bilingualism and biliteracy- and, to classrooms where bilingual children are present, but bilingualism is not fostered in the curriculum. One approach to categorizing types of bilingual education is to examine the aims of the various types. They may be divided into two general categories, such as transitional and maintenance bilingual education (Baker 1996). Transitional bilingual education aims to move the child from the language of home to the dominant majority language. Maintenance bilingual education aims to promote the minority language in the child. Developmental maintenance helps to acquire a student's L1 to full-proficiency and fullliteracy. Developmental maintenance is sometimes referred to as Enrichment Bilingual Education- a term that is also used for programs for language majority children who are adding second language at school. The research on bilingualism and the education of language minority 
children gets input from a number of perspectives. Educators, sociologists and political anthropologists all contribute to the debate. What is it that the linguist can bring to the debate? Does the field of linguistics present insights into the nature of languages that are unique? Those in the field of second language acquisition and bilingual education are usually interested in the development of language skills. These skills are observed by way of the acts of speaking, listening, reading, and writing. These are all aspects of language performance, or what people do with language. In Jaffna, bilingual education is practiced with a purpose of making the Tamil speaking children to acquire English and the development of this program depends on many things such as socio cultural, sociopolitical and socioeconomic aspects. In a society like Jaffna, Tamil with a well -established culture have different perspectives towards the bilingual program is practiced in Jaffna schools (Karunakaran, 2012:114).

\section{Methodology}

This study was a qualitative study and explorative approach was adapted in the study. The data was collected from bilingual and non-bilingual teachers and bilingual and non-bilingual learners from VGHS and JHLC. Explorative questionnaires, observation and informal interviews were the tools used for data collection. Thirty teachers [including bilingual and non-bilingual] and forty students [including bilingual and non-bilingual] from grade 10 were selected for the study from VGHS and JHLC. It was made sure that both female and male teachers were incorporated when selecting the subjects for the study. Vembady girls' high school and Jaffna Hindu Ladies' were chosen for the study as they are well-established and well reputed in the Jaffna city. Also, they have enough resources to offer a better bilingual program. These two schools are girls' school so that the subjects only represent the views of one gender. Students from four divisions were incorporated for the study. In these two schools, some subjects are taught in English and some other subjects are taught in vernacular. Also, they adapted mother tongue-based bilingual education. That is to say, English is used as a medium of instruction once the children complete their primary education in vernacular up to grade five.

\section{Bilingual Education from Teachers' Point of View}

In this study, questionnaires were administered to 30 teachers and twenty of them were interviewed to get more authentic data regarding the current bilingual practice implemented in JHLC and VGHS. They seem to have different opinions about the bilingual education implemented in these two schools.

\subsection{Achievement of the Goals of Bilingual Program}

The study shows that many bilingual and non-bilingual teachers have accepted the fact that bilingual educational practices did impact positively.

1) Learning more than one language helps learners understand relevant subjects at a satisfactory level;

2) Bilingual learners' linguistic competence is more;

3) They can refer to many books;

4) They are more confident;

5) They want to learn other languages;

6) They learn by heart easily;

7) Bilingual learners read a lot of books;

8) Parents also give a constant support in their studies; and

9) Bilingual get more information than vernacular learners.

To have complete picture of the current bilingual practices as seen in Jaffna, we need to observe continuously and this will help us to critically evaluate the success or failure of the program. The responses from bilingual teachers suggest two things :(1) they need to wait to study the progress of bilingual education; and (2) the objectives have been fairly met. A bilingual teacher from VGHS says

"We have to wait more to see the impact of bilingual education in Jaffna, but English is very vital for getting a good job in the private sector"

\subsection{Teaching Science Subjects in English}

People in Jaffna are pre-occupied with a notion that Science subjects should be taught in English only. The technical terms in the science texts are all in English and teaching them in vernacular is not easy. Moreover, a lot of supplementary books are available in English. A lot of the responses from teachers' questionnaires suggest that science subjects ought to be taught in English. A response from a bilingual teacher on the notion of teaching Science subjects in English is as follows: "A lot of Science books are written in English and English is the medium of instruction for higher studies".

The teachers mentioned the reasons in their questionnaires for teaching Science subjects in English medium:

1) Science terms are mostly in English

2) Students can read more English books for their reference

3) Teachers read English Science textbooks for reference and

4) Students can pursue their higher studies

\subsection{Background of Bilingual Children}

Bilingual students use English in their day to day life. This is where they show their distinctive character and this makes them different from the non-bilingual students. They 
look confident and decisive. Most of the bilingual teachers say one thing in common that bilingual students are from different backgrounds. According to one bilingual teacher from VGHS,

"We have students coming from all sections of the society. There is one child in grade $10 \mathrm{~A}$, and she is a daughter from a poor family and the best in the class."

In these two schools, admission to bilingual medium is given to children who successfully get a good mark in the selection test administered by the school. The test would reflect the actual English levels of the children and selection will be made accordingly. Bilingual teachers from both JHLC and VGHS agreed that the test is conducted with proper monitoring. A teacher from JHLC says: "Children who pass the scholarship exam vastly do well in the selection test and the test is conducted without any bias."

\subsection{Learning Environment}

Teachers in general do have a belief that only a few students naturally speak in English outside the school. A bilingual teacher from VGHS is of the view: "At home, English is intentionally spoken in order to learn and think in English and to better understand the information presented to them. If children only speak Tamil, they will struggle to understand educational content because the majority [of the content] is in English." Teachers' responses point out one thing that some students in the nonbilingual classes can speak English well, but they don't get chance to operate English for communication. In the words of a teacher: "English medium students and Tamil medium students come from in the same social set up. Bilingual students are studious to learn English, but some Tamil medium students acquire English because of their home environment and they can use English well. English medium students normally use English for conversation. They can do well, but Tamil medium students don't use English language for conversation." Bilingual students seem to be contributing to teaching and learning conditions in the classroom. Some of them have really excellent command of English and good knowledge in the content area. They do explain the difficult issues which teachers can't solve sometimes. In the words of a teacher: "They very often clear my confusion."

\subsection{Steps to Improve Bilingual Program}

It was said by the teachers of these two schools that very occasionally students in the bilingual program go back to vernacular medium and such cases are very less in number. A teacher from VGHS said: "In general, bilingual students perform well. Sometimes, some students after one or two years drop bilingual education".

A larger number of teachers made a point that the current bilingual program needs to be revamped to offer better bilingual program. There are problems like shortage of teachers, lack of training and so on. By and large, responses in questionnaires reveal the following suggestions made by the teachers:

1) Effective curriculum should be drafted;

2) Training programs for bilingual teachers should be conducted;

3) Links with international professional agencies should be made available for bilingual teachers;

4) Scholarships for professional development should be made available for bilingual teachers;

5) Conducive bilingual situation should be formed to use both languages adequately.

\subsection{Attitudes towards Bilingual Education}

Interviews with teachers do suggest one point that not all the parents in Jaffna support bilingual education. The educated parents do not show any interest in promoting bilingual education. This makes the children to have a negative attitude towards bilingual education. A teacher from JHLC says: "Some parents do their best to send their children to bilingual classes, but many are not keen. Specially, many educated parents are not interested. University teachers and others are not keen and they think like that."

A big space is found between teachers and administrative officers working in the department of education. Administrative staffs are expected to give all kinds of assistance and direction to the teachers in the schools. In Jaffna zone, administrative staffs like additional director of education and in -service advisors are supposed to monitor and supervise the teaching and learning conditions of the schools in Jaffna zone. The data imply one point that they do not do their duties satisfactorily. This results in minimizing the teachers' motivation and the guidance required for teachers is totally missed because of the indifference of the administrative officers. A teacher commented on the support of administrative staff as follows: "No one prepared teachers to be bilingual educators and they teach in English as they used to do because they find it easier to continue what they have been doing. That is why bilingual education has not yet been implemented effectively, though it has been almost 10 years since the officialization of the policy."

Some teachers have a speculation that bilingual students go forward and participate in the public events and they are always proud of being bilingual speakers. They gather a lot of information by all possible means whereas nonbilingual students have inferiority complex and do not participate in the social functions actively. A teacher from JHLC expresses her view on the personality of bilingual students and non -bilingual students as follows:

"Bilingual students have a speculation that they are better. Many are like that. Non-bilingual children also think bilingual learners are superior over non bilingual learners, although some of the non-bilingual children are good in English." 


\section{Bilingual Program from Students' Point of View}

Students from Grade ten in JHLC and VGHS were selected for this study. Totally students from four divisions were incorporated for the study. Interview and questionnaire were used to collect the data from these students. Responses from the questionnaires showed a concordance with the teachers' view that students in bilingual classes improved their English proficiency enormously. The students in bilingual classes mostly spoke in English and a few students in bilingual classes had problem to speak in English. However, they said that they could write well in English. Bilingual children generally write with fair amount of accuracy and fluency as they write more in the classes. This helps them to develop their writing rather than speaking. All the bilingual children learn from private tutors teaching in the private tuition classes. They also get a lot of opportunities to practice their English with teachers and students. Students' responses reiterate one thing that they get a fairly good environment to practice their English in tuition classes. In this regard, Genesee (1994) has a view that good interaction enhances the language acquisition. Bilingual children speak English very often but students in the vernacular medium generally tend to use their mother tongue. Some non- bilingual students speak English because of their family background. Most of the bilingual education children have a positive attitude towards bilingual education.

\subsection{English for Communication}

Students are of the view that bilingual teachers do not interact with them in English adequately. Some teachers do not use English adequately in the classroom in these two schools. This makes students de-motivate language learning and they could get adequate comprehensible input. Students put their trust on the tutors teaching in the private tuition classes because they interact with them in English very often. A bilingual student from JHLC said: "Teachers have to teach in English, but many do not have English competency but in tuition teachers mostly speak English."

A few teachers speak English in the classroom and this helps students understand well. It appears that they generalize the idea that all the teachers use English always for interaction quite competently. Also, some students have a piety to teachers and this preoccupied their mind. So , they do not say anything bad about teachers.

Bilingual children are improving their skills greatly after they have been enrolled in the bilingual classes. They all have mastered their English to large extent. One can witness the huge improvement in their speaking skill. Generally, in Jaffna there is very little chance for people to speak English. Though people could write in English, their speaking ability is low. In the case of bilingual education, they get some situation where they are compelled to use English. This made them improve their speaking ability with fair amount of accuracy and fluency. A response from a vernacular medium student authenticates this: "When I entered the bilingual classroom, speaking Tamil was prohibited and all the classes were taught in English. Tamil speakers were forced to speak English. Now, all the students from $6^{\text {th }}$ grade to 12 th grade learn English."

Some responses from bilingual students' questionnaires try to convey a point that they speak English outside the school. They make use of English for communication with their brothers and sisters. Nevertheless, most of the responses from bilingual and non-bilingual students emphasize that bilingual children use English outside the schools as and when it is necessary.

\subsection{Status of English}

Students' responses show that they are well-aware of the present position of English in the modern competitive labour market. They came out with some reasons for learning English with interest:

1) It is a global language

2) One requires English to study information technology

3) It serves as a link language

4) It helps to find good work opportunities

5) It is a second language in Sri Lanka

6) One requires it for his/her higher studies

Students' responses proves one point clearly that students in the bilingual classes acquired English after they had been enrolled in bilingual education. It is apparent that bilingual children read English newspapers and journal, newsletters, World History and Politics

Children discuss the issues pertaining to the bilingual education with parents and parents also give useful guidance when children choose bilingual education. In most cases, children made their decision on their own to go for bilingual education. Sometime they are confused as to what to do for advanced level education once they pass their ordinary level. The advanced level exam is very competitive one and it determines the university entrance of the students.

Data show that some vernacular medium students are fairly good in English but still carry on their studies in vernacular medium. Parents of some of these children are not educated and aware of the advantages of bilingual education too. So, children are not guided properly and they go for vernacular medium classes even if they are good in English.

These students during the interviews disclosed the following reasons for not choosing bilingual education:

1) Bilingual education requires a lot money

2) Parents are ignorant

3) Parents are illiterate , so that they do not persuade their children for bilingual education

\subsection{Bilingual Education and Biculturalism}

Language and culture are inseparable (Willett, 1995:35435 cited in Mickan, 2006:345). Bilingual children have 
changed their clothes, and they put on clothes which are very stylish and very neat. They seem to think that English speaking people are always stylish and neat. This aspect was found among the highly Anglicized people in Sri Lanka during the colonial time and Anglicized people adapted the life style of British people (Fernando, 1977). In Jaffna too, bilingual children want to show that they are different from others by wearing neat and good looking dress and also they interact with friends in English deliberately. A student from vernacular medium described it in her words: "Bilingual students are stylish and good looking" Bilingualism also leads to biculturalism (Fishman, 1968). It is very interesting to note here Students from low socio-economic background outperform the students from high socio-economic background. According to Genesee (2003), socio-economically disadvantaged students have some difficulty in scoring higher grades in bilingual or immersion programs, but her findings do not comply with the bilingual children from socio-economically disadvantaged background in Jaffna. Generally, parents in Jaffna take keen interest in their children's education. They monitor the practice of bilingual education in the schools and advocate the viable solutions when problems arise. They motivate their children to go for bilingual education.

\section{Socio-Cultural Factors and Language Acquisition}

It is vital to look at the factors influencing language acquisition. The factors which influence language acquisition in Jaffna include the aspects like medium of instruction, family, government, students, friends and the public's perception of Tamils. All bilingual learners understood the importance of bilingual speech themselves. That is to say, the bilingual learners conceded the fact that to learn English, it is very imperative that the students themselves must have positive attitudes towards learning English. The second factor that was conceded importance by the bilingual learners was family. Bilingual learners considered Family as the prime factor in the acquisition of English. The Tamil philosophy is emphasizing on the family as the fundamental unit that passes down linguistic and cultural heritage. If the family is not sustaining the acquisition of English, the children will not be encouraged to pick up English. External environment too have a big role to play in the acquisition of English. This is not surprising particularly when English language is not used for interaction in Jaffna.

It is worth mentioning that in spite of the differences, all the students considered the government as rather less important factor in language acquisition. This means that Jaffna students accept that there is a very partial contribution that the government can be render with regard to language acquisition. The Bilingual Approach of changing the medium of instruction to include English in the classroom is witnessed as contributing highest to the acquisition of English. In fact, all the groups rated the medium of instruction as significantly very important as all the other factors.

This study brings out that the governmental initiatives are perceived as essential to the acquisition of English among school children. Also, serious attention could perhaps be directed to highlight to both parents and students that language acquisition rely principally on their own attitudes and practices and that this is a mindful decision that they need to make and commit themselves to progress in grasping their English faster.

\section{Findings}

This research helped to articulate some of the multilayered issues that influence the implementation of Tamil-English bilingual education Jaffna schools.

\subsection{Students'Mark Sheets}

In order to support the positive effect by the bilingual program, students' mark sheets of bilingual and nonbilingual students from JHLC and VGHS were taken for analysis. The bilingual students scored good grades in each subject than those of non-bilingual students. Subjects such as Science \& technology, Math, Environmental Studies, Health and Physical Education, History, Geography and civics are taught in English and bilingual children performed well in these subjects. For example, in the bilingual class grade $10 \mathrm{~A}$ in VGHS out of 30 children 23 got $80 \%$ average or more, but in non-bilingual class grade $10 \mathrm{D}$ out of 35 children 18 got the average $80 \%$ average or more . Correspondingly, in the bilingual class, grade 10A, in JHLC, out of 35 children 29 got $80 \%$ average or more, and in the non-bilingual class, grade $10 \mathrm{D}$, out of 40 children 18 got $80 \%$ or more on average. In ESL too, bilingual children from both schools got good grades than non-bilingual children.

\subsection{Acquisition of English}

With respect to language spoken at home, in some families English is favored, as it is positioned as instrumental in improving children's education. Comments by the students and teachers suggested that English acquisition is crucial to academic and social success. The value of Tamil in Jaffna society is indisputable. Both English and Tamil are important, but academically and socially, English has more advantage. There was no equity between English and Tamil, despite the linguistic reality that Tamil is demographically dominant. There are Tamils but they never argued that Tamil hindered English acquisition. It is a question of increasing one's probability of success. That is to say, good use of English is a requisite for finding a job.

In regard to the school setting, some interviewees' answers reflected positive views toward the policy change. The policy change also appeared beneficial with regard to 
children's psychosocial well-being. Students seemed more open and more comfortable in the classroom now. Students were more participatory and more expressive because bilingual method is adapted for teaching some subjects.

\subsection{Ideological and Attitudinal Gaps}

There were ideological and attitudinal gaps between Tamil and English that may fragment bilingual education policy between the policy level (i.e., policy makers and intellectuals) and the operational level (i.e., parents and teachers) Regarding the ideological and attitudinal gaps between the policy level and the operational level, while policy makers and intellectuals support English as the language of instruction and the Tamil -English bilingual policy, some parents and teachers tend to favor Tamil over English in part because the instrumental value of English is considered to surpass that of Tamil. Many parents and teachers were concerned about their children's and students' English acquisition. They seemed to believe that the use of Tamil at home or school might impede children's acquisition of English, and might have negative impact on their academic performance.

\section{Recommendations}

Bilingual teacher training which includes the study of second language acquisition and other language learning theories will be a key for an successful implementation of Tamil - English bilingual education in Sri Lanka. Bilingually trained teachers with knowledge of second language acquisition theories may help to re-educate parents through school meetings and community programs about the benefits of learning first in one's native language before acquiring proficiency in a second language and of the importance of parental roles in proper language development.

Discrepancy in opinion between policy makers and intellectuals may cause confusion and disrupt the implementation of bilingual policy. It is thus encouraged to engage policy makers and intellectuals in policy dialogue, so that they can agree upon a policy for an adequate implementation of Tamil -English bilingual education.

\section{Conclusion}

The relevant data to discuss the research questions of this study were collected from the two schools and the analysis of data shows the different perspectives on bilingual education -students and teachers. The data shows that bilingual education has produced a lot of good effects for students, and though there are shortcomings and impediments, the bilingual education has produced an optimistic mental picture that it would be complete in the years to come.

\section{References}

[1] Baker, C. (1996). Foundation of Bilingual Education and Bilingualism. Clevedon, UK: Bath Press.

[2] Baker, D. (2003). Bilingual Education. Retrieved from http:/homepages w mich.edu/ d2ba ker/bilingualeducation.pdf

[3] Fernando, C. (1977). English and Sinhala bilingualism in Sri Lanka. Language in Society, 6: 341-60.

[4] Fishman, J. A. (1968). Language Problems and Types of Political and Sociocultural Integration: a conceptual postscript. In J. Fishman, C. Ferguson, \& J. Gupta (Eds.), Language Problems of Developing Nations (pp. 491-498). New York:John Wiley \& Sons, Inc.

[5] Fishman, Joshua A. (1968). Nationality-Nationalism and Nation-Nationism. In Joshua A. Fishman, Charles A. Ferguson \& Jyotirindra Das Gupta (Eds.), Language Problems of Developing Nations (pp. 39-51). New York: John Wiley \& Sons,Inc.

[6] Genesee, F. (Ed.). (1994). Educating Second Language Children: The Whole Child, TheWhole Curriculum, and The Whole Community. New York: Cambridge Press.

[7] Genesee, F. (2004) . What Do We Know about Bilingual Education for Majority Students? In T. K. Bhatia \& W, Ritchie (Eds.), Handbook of Bilingualism (pp. 547-576). Malden, MA: Blackwell.

[8] Karunakaran, T. (2012). Sociocultural Factors and Bilingual Education in Jaffna. Lamburt Academic Publishing, AV Akademikerverlag GmbH\& Co. KG Heinrich-Böcking-Str. 6-8,66121, Saarbrücken, Germany, pp.112-114.

[9] Mickan, P. (2006). Socialisation Through Teacher Talk in an Australian Bilingual Class. The International Journal of Bilingual Education and Bilingualism Vol.9, No. 3.pp.342358. 